\title{
Coronary Risk Factors in Female Patients With CAD
}

\author{
Dr. Prabin Adhikari
}

NAMS, Bir Hospital, Kathmandu, Nepal

\section{Study Objective}

This study was conducted to study the association of risk factors for coronary heart diseases in female population. Subjects were included from patients attending three major hospitals within Kathmandu. Patient characteristics were noted and statistical association were sought.

\section{Study Design}

The present study is a cross- sectional, non-interventional, observational study.

\section{Methodology}

Study was conducted at Shahid Gangalal National Heart Centre (SGHNC), National Academy of Medical Sciences (NAMS) Bir Hospital and Shree Birendra Army Hospital, 100 consecutive patients were enrolled. All the patients included were either having ST elevation MI, Non ST elevation MI or having angiographically proven CAD. The study period was one year. Patient's particulars noted and physical examinations were done in the OPD/Emergency departments. Standard laboratory and imaging modalities were employed. Historical, clinical and laboratory findings were analyzed as per criteria set by $\mathrm{WHO}, \mathrm{ACC} / \mathrm{AHA}$, NCEP to decide if that constitutes a risk factor. Statistical analysis was done using SPSS 11.5.

\section{Results}

Mean age of presentation was 61 years with urban dominance (56\%). Smoking and menopause were significantly associated with coronary artery disease in the study population (Chi square $=5.760,54.7 \mathrm{p}=0.01,<0.001$ respectively), $25 \%$ of the study subjects were diabetic. Diabetes was significantly associated with CAD (Chi Square $=25$, $\mathrm{p}<0.001)$. $10 \%$ of the study population had family history of premature CAD. Those who had family history of CAD had mean age of presentation as 52 years. Age of presentation and family history of premature CAD correlates significantly (Pearson Correlation = $-0.204, p=0.041)$. Average height and weight of the study population were $153 \mathrm{~cm}$ and 
$63 \mathrm{Kg}$ respectively. Mean BMI of the presenting subjects was $26.92 \mathrm{Kg} / \mathrm{m}^{2}$, which was statistically significant $(p<0.001)$. Mean waist circumference and waist hip ratio were 93 $\mathrm{cm}$ and 0.95 respectively; both the values were statistically significant $(p<0.001, p<0.001$ respectively), Mean fasting blood sugar was $123.5 \mathrm{mg} / \mathrm{dl}$. Mean total cholesterol, HDL, LDL and TG were $194 \mathrm{mg} \%, 41 \mathrm{mg} \%, 112 \mathrm{mg} \%$ and $181 \mathrm{mg} \%$ respectively, Significantly High levels of LDL cholesterol $(p<0.001)$ and TG $(p<0.001)$ were seen. High incidence $(67 \%)$ of metabolic syndrome was found in this population.

\section{Conclusion}

Nepalese women who had CAD are mostly post-menopausal. Cigarette smoking, hypertension and diabetes were significantly associated with CAD in this population. Their BMI is high as compare to the Asian standards. They had statistically significant waist hip ratio. Lipid profile was significantly altered and $67 \%$ of them fulfill the criteria for metabolic syndrome. This study points out the fact that we are not different than developed countries regarding risk factors for CAD. We need to have more studies in this field and develop a strategy to combat this problem. 